\title{
EDUCAÇÃO EM DIREITOS HUMANOS E O PAPEL DO MINISTÉRIO PÚBLICO NA CONSOLIDAÇÃO DO DIREITO À EDUCAÇÃO
}

\author{
Antônio Germano Ramalho* \\ Ana Carolina Gondim de A.O. Ramalho**
}

RESUMO: Este artigo apresentou uma revisão bibliográfica sobre o papel do Ministério Público na salvaguarda do direito à educação como pilastra à efetivação dos direitos humanos. A consolidação da educação impõe ao Estado políticas públicas exequíveis em consonância com o ordenamento constitucional e uma das providências para o resguardo da cidadania brasileira é a participação diligente do Ministério Público na defesa dos direitos fundamentais proporcionando o empoderamento cognitivo e político do indivíduo no sentido de transformálos em cidadãos efetivamente. Aludida instituição se apresenta como instrumento de amparo às pretensões sociais, fiscalizando a atuação político-pedagógica e administrativa das instituições de ensino.

PALAVRAS-CHAVES: Direitos humanos; direito à educação; educação em direitos humanos; Ministério Público; cidadania.

\section{EDUCATION ON HUMAN RIGHTS AND THE ROLE OF THE PUBLIC MINISTRY IN THE CONSOLIDATION OF THE RIGHT TO EDUCATION}

ABSTRACT: This article presented a bibliographical review on the role of the Public Ministry in defending the right to education as a basis for the implementation of human rights. The consolidation of education imposes on the State possible public policies in accordance with the constitutional order and one of the measures for the protection of Brazilian citizenship is the diligent participation of the Public Ministry in the defense of fundamental rights, providing the individual's cognitive and political empowerment in the sense of transforming them into citizens effectively. This institution is presented as an instrument to protect social pretensions, supervising the political-pedagogical and administrative performance of educational institutions.

KEYWORDS: Human rights, right to education, human rights education, Public Ministry, citizenship.

\section{INTRODUÇÃO}

\footnotetext{
*Doutor em Educação pela Universidade Federal da Paraíba (UFPB), cuja tese trata de Educação Jurídica. Mestre em Direito Constitucional pela Universidade Federal do Ceará (UFC). Professor de Direito da Universidade Estadual da Paraíba (UEPB) e da Faculdade de Ensino Superior da Paraíba (FESP). E-mail: agermanoramalho@gmail.com.

** Mestre em Direito, na área de concentração em Direitos Humanos pela Universidade Federal da Paraíba (UFPB). Professora do Curso de Direito da Faculdade de Ensino Superior da Paraíba (FESP), onde também é responsável pela Coordenação de Pesquisa e Extensão. E-mail: anagondim30@ hotmail.com.
} 
Historicamente a educação nem sempre foi considerada um direito da pessoa humana, de modo universal, sendo alçada a esta condição apenas a partir da positivação dos direitos sociais no início do século XX. No Brasil, a educação primária gratuita é responsabilidade do Estado desde o período imperial (SILVEIRA, 2009). Todavia, apenas com a vigência da Constituição de 1934, de modo inédito, se afirmou a educação como direito de todos e estabeleceu que a efetivação deste fosse responsabilidade do Estado e das famílias. A Constituição de 1946 reitera a educação como direito de todos os cidadãos, impondo que esta deveria ser eficiente (CURY, 2014).

Por sua vez, a Constituição de 1988 assegura a educação como direito fundamental para a cidadania brasileira, envolvendo o Estado, a família e a sociedade como instituições coresponsáveis por sua promoção e efetivação (art. 205 da CF/88), uma vez que a postura do Constituinte de 1987 se ancorou no movimento mundial de promoção e proteção da educação como direito planetário conforme o preceituado na Declaração Universal dos Direitos Humanos (DUDH/1948).

A Constituição Cidadã afirmou vigorosamente os direitos humanos, impondo ao Estado brasileiro a obrigação de defender e proteger os direitos fundamentais e responder às demandas de diferentes movimentos sociais, ampliando progressivamente a inclusão de novos temas em suas preocupações (CANDAU, 2012). Portanto, na atualidade, e por força constitucional, o Brasil possui significativo conjunto normativo que impõe o incremento de políticas públicas centradas na proteção e promoção dos direitos humanos.

Ademais, além da Declaração Universal dos Direitos Humanos (DUDH/1948), outros instrumentos normativos internacionais consagram a educação como direito humano, a exemplo do Pacto Internacional de Direitos Econômicos, Sociais e Culturais (PIDESC, 1966), em seu art. 13; do Protocolo Adicional à Convenção Americana sobre Direitos Humanos, nominado Protocolo de São Salvador (1988), igualmente em seu art. 13, dentre outras normas internacionais.

O direito à educação, consoante a DUDH (1948) é o meio ou expressão de reconhecimento da dignidade da pessoa, “[...] inerente a todos os membros da família humana e de seus direitos iguais e inalienáveis" (CURY, 2014, p. 1057), materializando-se como a gênese para a consciência do ser humano e de sua existência, como tal, e, por conseguinte, do reconhecimento do outro como igual em dignidade, oportunidades e direitos. 
À vista disto, a falta de acesso à educação compromete o próprio discurso dos direitos humanos e sua efetivação, posto que sem conhecimento não se constrói cidadania e, por sua vez, sem cidadania não há empoderamento, porquanto este, nas lutas sociais, está vinculado à educação de índole emancipadora e libertadora (BARBOSA; MÜHLI, 2016) e a consequente consciência do cidadão da necessidade de buscar os meios legais para que o Estado cumpra suas obrigações constitucionais de acordo com o que preceitua a Constituição Federal (1988), uma vez que empoderar, consoante aduz Barbosa e Mühli (2016), significa aumentar a capacidade das pessoas, individual ou coletivamente, de influenciar a sua realidade segundo as suas pretensões.

Não obstante, ao empoderamente político deve preceder o empoderamento cognitivo proporcionado pela educação. E, neste sentido, certifica Freire (1987), o poder ou a capacidade de compreender a realidade social afeta a vida das pessoas, e, apenas a partir do empoderamento intelectual ou cognitivo os indivíduos são capazes de compreender sua condição de subalternos na sociedade e desenvolver uma consciência crítica para transformar sua realidade.

Nessa perspectiva, a "[...] pedagogia do empoderamento" (BARBOSA; MÜHLI, 2016, p. 799) é relevante e determinante na luta pelo reconhecimento jurídico dos direitos de cidadania. Isto posto, num Estado fundado no princípio da democracia e da cidadania (art. $1^{\circ}$, caput, II, CF/88) não se pode tratar de direitos humanos e de sua consequente efetivação dissociado da educação, uma vez que este se consubstancia como um direito - meio, cujo objetivo é impedir que ocorra o "[...] emagrecimento dos direitos de cidadania”, uma vez que a educação é “[...] fonte de proteção e preservação dos indivíduos na sua integridade física, mental e social" (FERREIRA, 2014, p. 420).

Nesta seara, educar para cidadania e emancipação significa educar para o respeito e a consolidação dos direitos humanos, no sentido de:

[...] afetar a "naturalidade" e "normalidade" das violações trazidas pelos processos de colonização e ditaduras; ter uma intervenção sistemática na formação de valores e hábitos promotores da dignidade e das liberdades fundamentais; fortalecer as estratégias dos movimentos sociais e a dimensão axiológica da ação transformadora; promover o pluralismo político, fortalecer o regime democrático e o respeito aos direitos humanos; erradicar e transformar o autoritarismo institucional; educar a sociedade e os agentes públicos para a relação entre direitos humanos e democracia; combater todas as formas de violações e discriminações; promover o direito à memória e à verdade (ZENAIDE, 2016, p. 56). 
E, para que a sociedade alcance todos os objetivos acima descritos, a participação do Estado na promoção da educação voltada para a solidificação da dignidade da pessoa humana é essencial e significa educar em Direitos Humanos, quando se estabelece como princípios para as políticas educacionais: a dignidade, a cidadania e a liberdade (arts, $1^{\circ}, 3^{\circ}$ e $5^{\circ}, \mathrm{CF} / 88$ ). Por conseguinte, tais valores somente se constroem na trilha de ações concretas promovidas a partir do Estado político e gestor, pois em essência o seu papel é o de realizar a felicidade pelo bem-estar social ancorado no mais célebre princípio normativo constitucional: a dignidade da pessoa humana (art. $1^{\circ}, \mathrm{III}, \mathrm{CF} / 88$ ), considerado como o valor norteador de todas as ações em respeito à existência do indivíduo, que traz em seu bojo o espectro de valores morais inerentes ao ser humano e que se manifesta em toda pessoa com vida, exigindo respeito por parte dos demais e do Estado.

Ainda nesta perspectiva, a dignidade da pessoa humana é considerada como cláusula pétrea da Carta Constitucional brasileira, concomitantemente, se transforma em obrigação estatal nas providências públicas que devem ser tomadas no sentido de permitir ao cidadão construir, através da educação e da cultura, a afirmação desta dignidade como direitos garantidos.

Isto posto, consumar a dignidade da pessoa humana requer por parte do Estado ações positivas e políticas públicas exequíveis em consonância com o ordenamento constitucional e, neste sentido, uma das providências para o resguardo da cidadania brasileira é a participação do Ministério Público no monitoramento e na defesa dos direitos que tangem a cidadania nacional, em virtude de seu perfil e atribuições institucionais, pois, corrobora Martins Junior (2002) que esta entidade trata-se de estrutura independente, cuja eficiência e prestígio social estão vinculados a sua competência para exigir o implemento das políticas públicas dos Poderes Executivo e Legislativo a partir da captação da realidade social ou mediante processos de aproximação com a população para canalização de suas demandas.

Hodiernamente, por força da Carta de 1988, o Ministério Público possui atribuições mais largas do que a da acusação penal, sendo alçado à condição de guardião dos direitos individuais indisponíveis e dos coletivos, atuando em searas múltiplas, tais como: eleições, direitos do consumidor, meio ambiente, saúde, povos indígenas, patrimônio histórico, atividades policiais, prisões e, também, na educação, dentre outros (SADEK, 2010). Para tanto, a referida instituição tornou-se responsável pela garantia da ordem jurídica, do regime democrático e dos interesses sociais. 
Para tanto, qual o papel do Ministério Público na promoção dos direitos humanos, particularmente do direito à educação? O Ministério Público é instrumento para consolidação da educação voltada para os direitos humanos, em cooperação com as instituições educacionais, como poderoso garantidor de direitos e instrumento de justiça para as camadas vulneráveis da população?

Este artigo apresenta uma revisão bibliográfica sobre o papel do Ministério Público na salvaguarda da cidadania através do direito à educação, como instrumento fiador dos direitos humanos, o qual se fundamentou na concepção constitucional de que as atribuições do Ministério Público ultrapassam a fiscalização legal, tão somente, e estão ancoradas na promoção da cidadania, tal qual um canal para as demandas sociais, além de promover a justiça e o bem-comum, consubstanciando-se como um porta-voz para a sociedade.

Para a contextualização e a análise do problema realizou-se levantamento bibliográfico através de fontes científicas, procedentes de livros e artigos publicados em periódicos científicos nacionais e internacionais indexados nas bases de dados Bireme, Latindex e Scielo, assim como em legislações e outras fontes (revistas, sites, dentre outros) publicadas. A pesquisa foi realizada no período de maio a julho de 2017 e os estudos foram selecionados a partir dos descritores "educação", "educação em direitos humanos", "ministério público e direitos de cidadania", "empoderamento cognitivo", "empoderamento político", "educação e dignidade humana". Utilizou-se como critério de inclusão resumos e artigos, na íntegra, publicados em português e espanhol, no período de 2002 a 2016. Como critério de exclusão definiu-se as referências bibliográficas que não respondiam a questão norteadora. Ao final da investigação científica, a análise foi composta de 28 referências. No que alude aos aspectos éticos da pesquisa, o estudo garante as citações das autorias e das fontes bibliográficas utilizadas para elaboração deste manuscrito.

Após o levantamento bibliográfico, foi feita uma leitura exploratória com o intento de verificar a relevância das obras consultadas para o estudo. Em seguida, realizou-se uma leitura seletiva das informações, de modo a eleger elementos capazes de responder ao objetivo da pesquisa. Posteriormente, empreendeu-se a leitura analítica, com o intuito de ordenar e sistematizar os dados obtidos nas fontes de pesquisa para a apreensão do conhecimento sobre o direito à educação, voltado à educação em direitos humanos e sua interface com o papel institucional do Ministério Público. Sucessivamente, procedeu-se a leitura reflexiva e interpretativa dos textos, com a finalidade de conferir significados mais amplos dos resultados 
obtidos e relacionar as ideias expressas nas obras consultadas com o problema pesquisado. Por fim, efetuou-se a síntese integradora do material investigado que será apresentada em duas categorias de análise, que dão título às duas seções que seguem, respectivamente: "Educação e Direito: educação em direitos humanos e cidadania" e "O papel do Ministério Público em face do direito à educação".

Para tanto, o objetivo deste manuscrito foi refletir sobre o papel do Ministério Público como instrumento para consolidar a cidadania através da educação em direitos humanos.

\section{EDUCAÇÃO E DIREITO: EDUCAÇÃO EM DIREITOS HUMANOS E CIDADANIA}

A ligação entre os direitos humanos e o direito à educação tem sido alvo de inúmeras produções científicas que utilizam os mais variados caminhos de fundamentação para enraizar no pensamento ocidental a importância de tratar ambos com prioridade. Neste sentido, Mccowan (2015) reitera que o citado direito se caracteriza, na atualidade, como um grande consenso popular quanto à sua existência e sua importância, posto que através da educação o ser humano desenvolve habilidades, conhecimentos e valores, compreende que é sujeito de direitos e o que isto significa, portanto, discerne o que são direitos e passa a ser capaz de reivindicá-los e exercê-los.

Nesta perspectiva, o direito à educação se tornou, com o avançar do século XX, tão importante quanto o direito à vida, à liberdade e à igualdade, pois consiste em uma contínua construção e reconstrução que tem por fim melhorar a qualidade da experiência humana através da inteligência (SILVA; MASSON, 2015).

Inicialmente, o direito à educação perpassa o acesso à educação e, ulteriormente, o acesso à educação de qualidade, capaz de forjar o indivíduo para a cidadania. Neste sentido Candau (2012) alerta que apesar de existirem muitas referências à importância do direito à educação, as reflexões sobre o seu conteúdo deixam a desejar, posto que o ato de educar ainda é concebido a partir de entendimento exíguo, pois, se reduziu, historicamente, educação à escolarização. Contudo, afiança que o processo de desenvolvimento do direito à educação no Brasil sofreu um processo acelerado nas últimas décadas e pode ser caracterizado por duas vertentes: inicialmente a expansão da escolarização e, em seguida, a construção de uma educação escolar comum a todos, no sentido da afirmação da igualdade. 
Por conseguinte, o papel da educação é de essencial importância porque só através desta que as pessoas podem se empoderar e partir em busca da efetivação de outros tantos direitos que, justapostos, salvaguardarão a dignidade humana. E, consoante Mccowan (2015) isto é possível porque a educação possibilita o processo de compreensão do mundo e de nós mesmos, facilitando a sobrevivência básica na sociedade e na convivência com os outros, ou seja, a educação proporciona a aptidão de perceber e entender.

A ausência de educação ou a educação deficitária, incapaz de formar, sobretudo, o cidadão, esvazia a possibilidade de análise, de reflexão, de crítica e descortinamento da realidade e, consequentemente, de resistência e reivindicação, exaurindo o conteúdo constitucional no que tange aos direitos humanos, posto que os preceitos constitucionais só vivificam quando o cidadão usufrui de seus direitos. Portanto, alcançar este desiderato significa fazer valer o princípio da dignidade da pessoa humana.

Nunca é demais repetir que o Estado Democrático de Direito adotado pelo constituinte brasileiro em 1988, radica-se neste valor e dimensão antropocêntricas centrais. Desta forma, em todas as suas manifestações, deve o Estado Democrático de Direito estabelecer seu alicerce primeiro e sua razão maior na dignidade da pessoa humana (RANGEL, 2008, p. 43).

Deste modo, o status de direito constitucional, por si só, não é suficiente para que o direito à educação seja efetivamente garantido. Educar é um ato composto de muitas etapas e para a sua consumação é necessário a implantação de políticas públicas legítimas e com a segurança de recursos financeiros disponibilizados. Conforme o argumento de Mccowan (2015), além de ser um direito em si, a educação é suporte para outros aspectos do bem-estar social, que se consubstanciam também como direitos, a exemplo da saúde, do planejamento familiar, do emprego, dentre outros. Para tanto, sua efetivação ocorre a partir do, igualmente, direito ao acesso a educação e aos processos educativos ancorados na multiculturalidade (direitos culturais) de cada população. Por conseguinte, o direito à educação deve estar em conformidade com outros direitos humanos, de modo que se respeite os costumes, a religiosidade e a liberdade de pensamento dos educandos e sua vivência.

A educação em qualquer perspectiva representará um direito intrínseco à pessoa humana como instrumento de identidade do indivíduo e da sociedade a qual ele esteja vinculado por traços que o ligam ao universo da diversidade humana. A educação nos consolida como cidadãos e, simultaneamente, é meio que alicerça os direitos humanos. Nas 
palavras de Candau (2012, p. 721), a educação "Deve ter como horizonte a construção de uma cidadania participativa, a formação de sujeitos de direito, o desenvolvimento da vocação humana de todas as pessoas nela implicadas".

Para tanto, educação também expressa educar para os direitos humanos, através da educação em direitos humanos, que, por sua vez, significa qualificar para a cidadania e a justiça social, com o propósito de favorecer a transformação social, robustecer os processos democráticos e a emancipação dos grupos sociais historicamente excluídos e a participação destes na formação e execução de políticas públicas que fortaleçam a cidadania participativa (MAGENDZO K, 2016). Neste ponto de vista, a educação em direitos humanos pressupõe processos de ensino e aprendizagem fundados nos princípios da emancipação, da educação para liberdade e autonomia dos sujeitos.

Sob este aspecto, é importante evidenciar que educação voltada para a promoção dos direitos humanos também é meio para a diminuição das disparidades sociais e para a redução das desigualdades intelectuais, consubstanciando assim, o Estado Democrático de Direito, posto que o conhecimento garante a liberdade intelectual, que vai além da liberdade física (COSTA, 2011).

E, neste diapasão, o direito à educação e a educação em direitos humanos foram se aproximando gradativamente e, na atualidade, esta é considerada como parte daquela, constituindo-se como elemento fundamental para a qualidade da educação (CANDAU, 2012).

Em vista disto, este caminho se consolida a partir de uma concordância internacional sobre a criação e execução de políticas voltadas à educação em direitos humanos e para a vida democrática, conforme sustenta Rodino (2003), a partir de novas ferramentas teóricometodológicas desenvolvidas e ofertadas, simultaneamente, aos sujeitos envolvidos neste processo reformador como meio de enriquecer a difícil tarefa de educar em e para os direitos humanos.

No Brasil, a educação em direitos humanos principia seu desenvolvimento ao final da década de 1980, contudo, as primeiras atividades a serem elaboradas foram promovidas por organizações não-governamentais, cujas providências estavam vinculadas ao movimento de redemocratização do país, perpassando pela urgência na afirmação dos direitos individuais e, por conseguinte, a construção de uma cidadania democrática. Com o advento da Constituição e o processo de consolidação da democracia, passa a fazer parte da agenda governamental, com o protagonismo do governo federal nos idos de 1990, a partir da elaboração de políticas 
públicas e das parcerias entre a sociedade civil e as entidades governamentais (CANDAU, 2012; ZENAIDE, 2016).

Desta forma, a educação em direitos humanos surge ainda no final do período ditatorial (1964-1985) e constituiu-se instrumento de construção da democracia e da cidadania. Nas palavras de Zenaide (2016, p. 45-47) “[...] a educação em direitos humanos brotou no seio da sociedade civil, ainda em tempos de ditadura, como uma modalidade de resistência e de sinalização de mudanças políticas em andamento" e "[...] passa a ser concebida como um direito humano fundamental"

Como está configurado no art. $2^{\circ}$ da Resolução no $1 / 2012$ do Conselho Nacional de Educação, a educação em direitos humanos é parte fundamental do direito à educação, consolidada por conceitos e práticas educativas fundadas nos direitos humanos por intermédio de todos os programas de promoção, proteção, defesa e aplicação na vida cotidiana e cidadã de sujeitos de direitos e de responsabilidades individuais e coletivas (BRASIL, 2012), a partir da confluência de direitos civis, políticos, sociais, econômicos, culturais e ambientais. Nesta perspectiva, a mencionada resolução reitera que a educação em direitos humanos tem como objetivo fundamental promover a transformação social e, por esta razão, passa a integrar o universo do direito à educação embasada nos princípios da dignidade da pessoa humana, da igualdade de direitos, do reconhecimento e valorização das diferenças e da diversidade, bem como da democracia.

Validando este posicionamento, Silva e Masson (2015) certificam que apenas a partir da educação a cidadania plena poderá ser alcançada, pois uma sociedade educada será composta de pessoas que conseguem reivindicar e conquistar espaços, individual e coletivamente. Por conseguinte, ainda ressaltam que a cidadania ativa apenas poderá ser concebida numa sociedade em que os cidadãos sejam livres e tenham igualdade de oportunidades, isto é, sejam respeitadas como seres humanos. E, neste desiderato, cabe ao Estado promover a união de esforços objetivando a efetivação dos direitos de cidadania, destacadamente, o direito à educação.

Sequenciando essa questão, é importante compreender que promover e consolidar as políticas educacionais voltadas para a educação em direitos humanos no século XXI perpassa as contribuições de Delors (2006), que considera o indivíduo como o mais significativo agente promotor de direitos humanos e, para tanto, deverá aprender a conhecer a si próprio e ao outro; a construir novas realidades quando se fizer necessário; bem como assimilar a viver 
com o outro em um mundo multicultural e a entender e respeitar a humanidade das demais pessoas.

Sob este ponto de vista, a educação possui papel inovador neste século, pois deverá fornecer os mapas de um mundo novo, complexo, exercendo a função de bússola que norteará o caminhar através dele. A proposta é que a educação se enraíze em quatro aprendizagens fundamentais que servirão de pilares do conhecimento para toda a vida das pessoas: aprender a conhecer - adquirir os instrumentos da compreensão; aprender a fazer - agir sobre o meio envolvente; aprender a viver juntos - a fim de participar e cooperar com os outros em todas as atividades humanas e; aprender a ser - via essencial que integra as três precedentes (DELORS, 2006).

Para tanto, o aprender a conhecer enceraria o domínio dos próprios instrumentos do conhecimento como meio e finalidade da vida humana, favorecendo o despertar da curiosidade intelectual, estimulando o sentido crítico, o que permitiria a aquisição de autonomia e a capacidade de discernir. Portanto, neste sentido, é essencial que os educandos, estejam onde estiverem, possam ter acesso, de forma adequada, às metodologias científicas que irão lhes proporcionar o exercício da atenção, da memória e do pensamento. Por sua vez, o aprender a fazer está vinculado a prática do que se apreendeu teoricamente, preparando o futuro profissional com técnicas apuradas para o desempenho de suas funções laborais (DELORS, 2006).

Por conseguinte, a vida profissional demanda a necessidade de vivência e compartilhamento, e, no sentido de complementar o 'fazer', observa-se o aprender a viver juntos, aprender a viver com os outros (DELORS, 2006). Invariavelmente, a convivência social poderá demandar algum tipo de conflito, contudo, estes não devem ser ignorados, pois são inerentes a humanidade no seu coexistir. Contrariamente, as contendas devem ser consideradas como uma possibilidade de crescimento e aprendizado, uma vez que educar em e para os direitos humanos pressupõe, consoante Rodino (2003, p.21), a “[...] resolução construtiva" do litígio por meio do diálogo e da conciliação, rejeitando a imposição dos argumentos de autoridade e da violência.

Desta forma, a escola pode produzir e reproduzir preconceitos, discriminações e desrespeito à diversidade cultural, mas, ao mesmo tempo, também pode ser o lugar de romper tais violações, contudo, esta providência é uma responsabilidade para os gestores escolares e 
educadores, comprometidos com a promoção e a concretização dos direitos humanos (CASTILHO, s/d, p. 6).

Neste diapasão, a educação deve ser capaz de evitar conflitos ou apresentar soluções pacíficas para estes, de modo, consoante aduz Rodino (2003), a obstar os fatores que podem fomentar embates, tais como o preconceito, a intolerância, a falta de diálogo e os argumentos de autoridade. À vista disto, o conflito pode ser compreendido também como um âmbito de aprendizagem e colaboração mútua.

E, para alcançar aludido escopo, Delors (2006, p. 99) sugere que a educação deve utilizar duas vertentes "No nível inicial um (pessoa) deve descobrir o outro (pessoa). Após esse primeiro contato e aprofundamento como nível seguinte, levar essas pessoas a tomar consciência de suas semelhanças e da interdependência entre todos os seres humanos do planeta [...]”, para tal, esta aprendizagem deve acontecer desde a educação infantil e estenderse até o ensino superior, com a participação da família, da escola e da sociedade.

Neste sentido, aprender a viver coletivamente, pressupõe a mobilização da autoreflexão e da auto-evolução, tanto de educadores como dos educandos, para que estes sempre avaliem suas condutas em torno dos princípios que norteiam a promoção dos direitos humanos e, por conseguinte, da dignidade da pessoa humana (RODINO, 2003).

\section{O PAPEL DO MINISTÉRIO PÚBLICO EM FACE DO DIREITO À EDUCAÇÃO}

O Ministério Público se posiciona na estrutura institucional da República Federativa do Brasil como instituição com as prerrogativas constitucionais de atuar como órgão fiscalizador, ao mesmo tempo em que deve acionar os dispositivos legais para fazer cumprir o que é de direito da sociedade e o que seja cogente ao Estado, portanto, funciona como mecanismo vigilante para fazer cumprir o Estado de Direito. Para tanto, conforme Castilho (s/d), como instituição do Estado brasileiro, responsável por zelar pelos direitos coletivos e individuais indisponíveis, tem a obrigação de monitorar as políticas públicas que visam concretizar os direitos humanos e, dentre estes, o direito à educação.

As funções e prerrogativas do Ministério Público e de seus membros, na qualidade de agentes públicos, estão contidas a partir do artigo 127 da Constituição Federal (1988). Estes, por conseguinte, exercem função essencial na jurisdição do Estado cabendo-lhes o dever de 
zelar pela ordem jurídica, o regime democrático e os interesses sociais e individuais indisponíveis.

Neste diapasão, conforme demonstra Bulos (2017), pode-se definir a Constituição Federal (1988) como a Constituição do Ministério Público, pois, o constituinte originário de 1987 deu especial atenção aos:

\begin{abstract}
Princípios e as garantias a que estão sujeitos os seus membros, a forma de nomeação e a autonomia dos procuradores-gerais, as funções institucionais, as normas fundamentais delineadoras dos caracteres da instituição foram predispostos em técnica jamais visa antes. Até o poder de iniciativa das leis, em certas matérias, atribuíram-lhe (art. 169), sem falar da capacidade de elaborar sua proposta orçamentária, com base nos limites impostos pela Lei de Diretrizes Orçamentárias. Não se lhe deu, contudo, a faculdade de iniciar proposta orçamentária, o que é da alçada do orçamento geral, submetido ao Legislativo pelo Executivo (BULOS, 2017, p.1144).
\end{abstract}

A decisão dos constituintes teve cunho de reparação histórica, posto que de modo inédito, por força constitucional, se formulou a estrutura de organização e de funcionalidade do órgão ministerial público, através de regras que apontam o seu funcionamento e as atribuições que lhes compete.

Esta reparação efetuou-se também pela mobilização do então Ministério Público desde os últimos anos da ditadura, iniciada em 1964, pois seus membros postularam junto à Assembleia Constituinte a ampliação de sua autonomia e de suas competências (LEMGRUBER, J. et al, 2016), compreendendo então, que a retomada e a consolidação futura da democracia brasileira estava, e ainda está, vinculada ao fortalecimento ministerial na defesa da cidadania nacional.

A partir da compreensão e da importância dos direitos sociais como estrutura imanente dos princípios inseridos na Carta Magna (1988), forçosamente fazem do Ministério Público o instrumento legítimo para defender a materialização destes direitos. E, neste sentido, o aludido Ministério deverá atentar para as desigualdades socioeconômicas que ainda, infelizmente, são observadas neste país, redundando no impedimento de milhares de brasileiros ao acesso a serviços considerados essenciais, a exemplo da educação, que não chega às áreas periféricas, e ainda assim quando chega não se faz sinônimo de eficiência e qualidade, esvaziando os preceitos constitucionais. Contudo, para a efetivação dos direitos sociais, imprescindível se faz a vontade política do Poder Público, traduzida em políticas públicas e ações governamentais. Nesta perspectiva, corrobora Marmelstein (2016, p. 72): 
A comunidade jurídica já percebeu que, sem o compromisso político e o engajamento social, a Constituição não passará de uma folha de papel, como dizia Lassale. Portanto, para que os direitos fundamentais sejam levados a sério, é necessário que a Constituição faça parte da vida dos indivíduos. Deve existir um dever de lealdade para com as normas constitucionais e a ordem de valores nela contida, independentemente de qualquer ideologia partidária. É o chamado "patriotismo constitucional".

O novo modelo de Estado Democrático de Direito, desenhado a partir da Constituição Federal (1988), transforma o perfil do Ministério Público e do próprio Poder Judiciário em instituições que não apenas devem garantir, simultaneamente, a fiscalização e a aplicação do direito, mas, se apresentem como entidades que trabalhem a partir da observância do equilíbrio dos interesses sociais, comprometidas com a consolidação dos direitos humanos e, conseguintemente, da justiça social.

Os constituintes de 1987 reforçaram os aludidos pressupostos ao oferecem ao Ministério Público a função histórica de exercer ao lado do cidadão o papel de controlador social, na medida em que atua como guardião dos interesses da sociedade, contra toda ordem de ações que tenham como desiderato atingir o corolário de bens jurídicos tutelados pela Constituição. Desta forma, o predito Ministério é obrigado a agir para garantir a ordem social e promover a justiça, no sentido de prevenir ou punir as omissões praticadas, principalmente pelo Estado (administrativo), bem como os abusos de conotação política, social e econômica realizados, eventualmente, pelos demais Poderes:

Afinal, são as Constituições que traçam as linhas mestras da sociedade, do
Estado e que fixam as regras fundamentais a serem observadas pelas leis
ordinárias. São as Constituições, enfim, a estrutura de um sistema jurídico a
ser seguido por determinada sociedade. Esta a razão para a presente análise,
referente ao papel do Ministério Público, partir de uma abordagem dos
dispositivos constitucionais. Assim, a Carta Magna garantiu a independência
do Ministério Público diante dos três Poderes do Estado (Legislativo,
Executivo e Judiciário), de forma nunca antes vista na história do
ordenamento político-administrativo do Brasil, além de ter dotado o
Ministério Público de autonomia orgânica e funcional, como de
funcionalidade independente (MOREIRA, 2007, p. 143).

A luta pelos direitos humanos, a partir da vigência da Constituição Federal (1988), tornou-se então responsabilidade, também, do Ministério Público, e dentre estes, a defesa do direito à educação como instrumento essencial de inclusão social e consolidação da igualdade, 
porquanto, o cidadão brasileiro ladeado pelo aludido Ministério deve guardar as premissas constitucionais e exercer o controle social com a providência de observar a legalidade dos atos do Poder Público. Por sua vez, importante ressaltar, cabe ao Ministério Público agir em defesa dos direitos constitucionais do cidadão adotando as devidas ações de cumprimento da ordem social e não permitir que omissões e abusos de poder sirvam de empecilho para a não consecução do conjunto normativo garantidor da dignidade da pessoa humana.

A contar da vigência da Constituição de 1988, o Ministério Público ampliou sua atuação e passou a trabalhar de forma planejada em defesa de diversos assuntos, e no que tange ao direito à educação se instaura inicialmente em alguns Estados da federação promotorias ou curadorias especializadas, a exemplo do Estado de São Paulo, Espírito Santo, Paraná, Rio Grande do Norte, Sergipe. Tais promotorias ou curadorias atuam em defesa do acesso à escola, monitorando e garantindo o número suficiente de vagas; observando a permanência dos estudantes nas unidades escolares, visando à prevenção da evasão e eivando esforços para a melhoria da qualidade do ensino (CASTILHO, s/d). Atualmente, vinte unidades federativas possuem promotorias ou curadorias especializadas na defesa do direito à educação (LEMGRUBER, J. et al, 2016, p. 24 ).

Ainda nesta perspectiva, na Federação, os promotores que se ocupam apenas dos direitos coletivos ou transindividuais ou os que se ocupam ao menos parcialmente dessa tarefa são os mais numerosos, chegando ao percentual de $63 \%$ dos representantes ministeriais. Tal atuação ocorre por meio do atendimento direto ao público (demandas e denúncias populares) ou mediado por organizações da sociedade civil, bem como através de outros meios, como a própria ouvidoria institucional, o "Disque-Denúncia" e, também, os meios midiáticos (LEMGRUBER, J. et al, 2016, p. 50 ).

Destarte, a atuação da instituição ministerial em face do direito à educação perpassa uma série de providências que requerem sua vigilância contumaz. Eivar esforços para garantir acesso à educação através das vagas em número suficiente; observar a permanência das crianças e adolescentes nos bancos escolares, e, lutar pela melhoria da qualidade do ensino são micro-providências na tutela deste direito. Além destas, outras medidas, de caráter mais amplo, macro-providências, devem ser pontuadas, a exemplo do que preceitua a Recomendação nº 44/2016 do Conselho Nacional do Ministério Público (CNMP) que dispõe sobre a atuação deste no que diz respeito ao controle com o dever de gastos mínimos com a educação, ao asseverar que os membros ministeriais devem empreender esforços 
administrativos e institucionais na defesa do custeio constitucional adequado do direito à educação $\left(\operatorname{art.} 2^{\circ}\right.$ ); além de acompanhar a execução orçamentária e financeira e as prestações de contas $\left(\operatorname{art} .3^{\circ}\right)$. Desta forma, o referido documento é de essencial importância para orientar a atuação da instituição na promoção e defesa do direito humano à educação.

Desta forma, o direito à educação e sua consequente garantia decorrem também da fiscalização dos orçamentos públicos e a correspondente destinação das verbas orçamentárias, tais como as oriundas de fundos e programas vinculados à educação, do ensino fundamental ao superior, a exemplo: do Fundo Nacional de Desenvolvimento da Educação (FNDE), Programa Nacional de Alimentação Escolar (PNAE); Fundo de Manutenção e Desenvolvimento da Educação Básica e de Valorização dos Profissionais da Educação (FUNDEB); Programa Dinheiro Direto na Escola (PDDE); Programa Nacional do Livro Didático (PNLD); Programa Nacional do Transporte Escolar (PNATE), dentre outros, além das verbas destinadas ao ensino superior e as de fomento a pós-graduação, através do fomento a pesquisa e as bolsas de estudo.

Em face, especificamente, do ensino fundamental, o Ministério Público tem atuação reiterada por força do Estatuto da Criança e do Adolescente (1990), quando o referido estatuto afiança que a educação é direito fundamental da infância e do juventude (SILVEIRA, 2009)

Cabe ao Ministério Público investigar e punir alguma eventual irregularidade ou ilegalidade em face da administração destes recursos, desde a execução de possíveis convênios entre os entes da federação, os repasses das verbas até as prestações de contas. Ademais, ao órgão ministerial cabe fiscalizar os Conselhos de Educação e a sua atuação, assim como se estes foram criados por lei, se estão de fato instalados e funcionando a contento, monitorando casuais omissões no cumprimento de suas atribuições legais (CABRAL, 2014).

Outra forma de garantir o direito à educação, através da atuação do Ministério Público, é a cooperação deste com a gestão democrática por intermédio da participação popular nos Conselhos Escolares, que são órgãos de participação democrática nas atividades administrativas e pedagógicas da escola, conforme o art. 14 da Lei $\mathrm{n}^{\circ}$ 9.394/96, dentre outros mecanismos que somados garantirão o acesso à educação, em todos os níveis, com qualidade e voltada à promoção da cidadania e dos direitos humanos.

\section{CONSIDERAÇÕES FINAIS}


No Brasil, o direito à educação foi alçado à condição de direito fundamental por força da Constituição de 1988 e responsabilidade dos municípios, dos Estados e da União, simultaneamente. Desde então, a sociedade brasileira tem empreendido esforços no sentido de vivenciar plenamente este direito. Contudo, o direito à educação ainda é relegado a um plano secundário, ainda compreendido como apenas o acesso aos bancos escolares públicos.

$\mathrm{Na}$ atualidade, educação é sinônimo de qualidade. Não basta que tenhamos direito à educação, esta tem que ser de qualidade, e tal exigência demanda esforços do poder público e da sociedade, além dos atores sociais que estão envolvidos diretamente com os processos de ensino-aprendizagem, a exemplo dos gestores, professores e alunos.

Ademais, a educação não se restringe a instrução, através do conhecimento técnico ou científico. Educar ultrapassa as barreiras da informação ou instrução e alcança a formação para a cidadania, posto que o direito à educação é considerado direito humano e como tal tem o desiderato de promover e proteger a dignidade da pessoa humana. Diante do desafio de ampliar o sentido da expressão "educação" em nossa sociedade, pensar apenas nesta como instrução limita a sua importância, posto que educação deve ser sinônimo de autonomia, liberdade, e, capacidade de reflexão e de ação em busca da defesa do bem-estar coletivo. Todavia, apesar de reconhecida em diversos instrumentos jurídicos internacionais e nacionais, a educação ainda necessita encontrar formas de efetivação. É preciso retirar o direito à educação da seara meramente teórica e buscar alcançar objetivos favoráveis a sua efetivação, para então se consagrar o conjunto de direitos em favor da pessoa humana, conforme a Declaração Universal dos Direitos Humanos (1948) e a Constituição da República do Brasil (1988).

No Brasil, um meio de proteção ao direito à educação é a atuação do Ministério Público, que por força constitucional, é competente e exerce o poder de monitorar e agir permanentemente em defesa do aludido direito, considerado como um bem maior da sociedade. Mesmo não sendo diretamente uma instituição considerada pela Constituição Federal (1988) como detentora do poder político, suas prerrogativas estão inseridas no título que trata sobre a organização dos poderes e distinto daqueles, sua função institucional extrapola os limites dos entes de poder se consubstanciando como instrumento promotor da democracia e da cidadania brasileira. 
No campo da educação, o Ministério Público tem exercido, de acordo com suas disponibilidades de pessoal e de recursos, atenção especial quanto ao acesso do cidadão à educação, a qualidade desta e a aplicação correta dos recursos destinados a este serviço, que deve ser, prioritariamente público, como meio de promover o desenvolvimento intelectual e cultural do cidadão brasileiro, do ensino fundamental ao superior, tanto na esfera administrativa como na judicial.

Todavia, a proteção à educação deve também ser prioridade para a aludida instituição, através da instauração de curadorias especializadas e da vigilância permanente sobre as Secretarias de Educação, as unidades e conselhos escolares, sejam estes, públicos ou privados, pois, o Ministério Público é a principal instituição para a realização dos direitos e das garantias constitucionais, se apresenta legitimamente como canal de amparo às pretensões sociais, fiscalizando a atuação político-pedagógica e administrativa das instituições de ensino, em todos os níveis, agindo de forma direta e efetiva para também contribuir com a efetivação dos planos e dos programas de Educação em Direitos Humanos de acordo com o discutido neste estudo.

\section{REFERÊNCIAS}

BARBOSA, M. G.; MÜHLI, E. H. Educação, empoderamento e lutas pelo reconhecimento: a questão dos direitos de cidadania. Educação e Pesquisa. São Paulo, v. 42, n. 3, p. 789-802, Jul./Set., 2016. Disponível em: < http://www.scielo.br/pdf/ep/v42n3/1517-9702-ep-42-30789.pdf>. Acesso: 11 Jul. 2017.

BRASIL. Constituição (1988). Constituição da República Federativa do Brasil. Brasília, DF: Senado, 1988.

. Ministério da Educação. Conselho Nacional de Educação. Resolução no 1/2012 de 30 de Maio de 2012. Estabelece Diretrizes Nacionais para a Educação em Direitos Humanos. Disponível em: <portal.mec.gov.br>. Acesso: 30 jun. 2017.

.Lei no 9.394/1996. Lei de Diretrizes e Bases da Educação. Estabelece as diretrizes e bases da educação nacional. Disponível em:< www.planalto.gov.br/ccivil_03/leis/L9394.htm>. Acesso: 30 jun. 2017.

Conselho Nacional do Ministério Público. Recomendação no 44/2016. Dispõe sobre a atuação do Ministério Público no controle do dever de gasto mínimo com educação. Disponível em:<www.cnmp.mp.br>. Acesso: 30 jun. 2017.

BULOS, U. L.. Curso de Direito Constitucional. 10. ed. São Paulo: Saraiva, 2017. 
CABRAL, K. M.. O Ministério Público Estadual e a justiciabilidade do direito à qualidade do ensino fundamental público no Brasil: funções e interpretações. Tese (Doutorado em Educação). Faculdade de Ciências e Tecnologia (UNESP). Universidade Estadual Paulista de Presidente Prudente, Presidente Prudente-SP, 2014. Disponível em: < <www.repositorio.unesp.br/handle/11449/123335>. Acesso: 11 jul. 2017.

CANDAU, V. M. F. Direito à educação, diversidade e educação em direitos humanos. Educação e Sociedade. Campinas, v. 33, n. 120, p. 715-726, Jul./Set, 2012. Disponível em:< http://www.scielo.br/pdf/es/v33n120/04.pdf>. Acesso: 11 jul. 2017.

CASTILHO, E. W. V. de C. Direito à educação e o ministério público. Disponível em:<www.dhnet.org.br/dados/textos/a_pdf/wiecko_direito_ed_mp.pdf >. Acesso: $10 \mathrm{Jul}$. 2017.

COSTA, Denise Souza. Direito fundamental à educação, democracia e desenvolvimento sustentável. Belo Horizonte: Fórum, 2011.

CURY, C.R.J. A qualidade da educação brasileira como direito. Educação e Sociedade. Campinas, v. 35, no. 129, p. 1053-1066, Out./Dez., 2014. Disponível em:

http://www.scielo.br/pdf/es/v35n129/0101-7330-es-35-129-01053.pdf. Acesso: 11 jul. 2017.

DELORS, J. Educação: um tesouro a descobrir. Relatório para a UNESCO da Comissão Internacional sobre Educação para o século XXI. 5. ed. São Paulo: Cortez, 2001.

FERREIRA, António. Política e sociedade: teoria social em tempo de austeridade. Lisboa: Vida Económica, 2014.

FREIRE, Paulo. Pedagogia do oprimido. 17. ed. Rio de Janeiro: Paz e Terra, 1987.

LEMGRUBER, J. et al. Ministério Público: guardião da democracia brasileira? Rio de Janeiro: Universidade Cândido Mendes, 2016. Disponível em:<www.ucamcesec.com.br〉. Acesso: 01 Jun. 2017.

MCCOWAN, T.O direito humano à aprendizagem e a aprendizagem dos direitos humanos. Educação em Revista, Curitiba, n. 55, p. 25-46, Jan./Mar. 2015. Disponível: <http://www.scielo.br/pdf/er/n55/0101-4358-er-55-00025.pdf>. Acesso: 01 Jun. 2017.

MARMELSTEIN, George. Curso de Direitos Fundamentais. 6. ed. São Paulo: Atlas, 2016.

MARTINS JUNIOR, W. P. MINISTÉRIO PÚBLICO, DEMOCRACIA E EFICIÊNCIA DA ATUAÇÃ. Revista Justitia. Anais do XXX Seminário Jurídico dos Grupos de Estudos da Associação Paulista do Ministério Público. São Paulo, 2002. Disponível em: <http://www.revistajustitia.com.br/artigos/zbxz58.pdf>. Acesso: 30 Jun. 2017.

MAGENDZO K., A. La educación en derechos humanos y la justicia social en educación. In: Cultura e educação em direitos humanos na América Latina. Coleção Direitos Humanos. Ana Maria Rodino et al (Orgs.). João Pessoa: CCTA, 2016, p. 221-251. Disponível 
em:<www.cchla.ufpb.br/.../2016/.../EBOOK-Cultura-e-EDH-América-Latina>. Acesso: 10 Jul. 2017.

MOREIRA, Orlando Rocha de. Políticas Públicas e Direito à Educação. Belo Horizonte: Fórum, 2007.

ORGANIZAÇÃO DAS NAÇÕES UNIDAS. Declaração Universal dos Direitos Humanos. 10 de dezembro de 1948. Disponível em: <www.onu.org.br/img/2014/09/DUDH.pdf>. Acesso: 15 Jul. 2017.

Pacto Internacional sobre Direitos Econômicos, Sociais e Culturais. 06 de dezembro de 1966. Disponível em: 〈www.unfpa.org.br/Arquivos/pacto_internacional.pdf>. Acesso: 15 Jul. 2017.

RANGEL, Rodrigo Costa Vidal. Educação constitucional, cidadania e estado democrático de direito. Porto Alegre: Núria Fabris, 2008.

RODINO, A. M. Educacion para la vida em democracia: contenidos y orientaciones metodológicas. Série Cuadernos Pedagógicos. San Jose da Costa Rica: Instituto Interamericano de Derechos Humanos, 2003. Disponível em: < http://www.iidh.ed.cr>. Acesso: 01 Jun. 2017.

SADEK, Maria Tereza (org.). O Ministério Público e a Justiça no Brasil. Rio de Janeiro: Centro Edelstein de Pesquisas Sociais, 2010. Disponível em: <www.bvce.org/DownloadArquivo.asp>. Acesso: 01 Jun. 2017.

SILVA, R. L. N da; MASSON, D. G. O direito fundamental social à educação como manifestação da igualdade e da liberdade, no contexto da política pública plano de desenvolvimento da educação (PDE). Revista Jurídica UNICURUTIBA, v. 4, nº 41, p.340362; Out./Dez, 2015. Disponível em:

<http://revista.unicuritiba.edu.br/index.php/RevJur/article/view/1465>. Acesso: 10 Jul. 2017.

SILVEIRA, A. A. D. Atuação do Ministério Público para proteção do direito à educação básica. In: RANIERI, N. B. S. (Coord.). Direito à educação. Aspectos constitucionais. São Paulo: EDIUSP, 2009, p. 123-145. Disponível em:< http://unesdoc.unesco.org/images/0018/001876/187688por.pdf〉. Acesso: 10 Jul. 2017.

ZENAIDE, M. DE N. T. A institucionalização da educação em direitos humanos na América Latina. A linha do tempo da educação em direitos humanos na América Latina. In: RODINO, A. M. et al (Orgs.). Cultura e educação em direitos humanos na América Latina. Coleção Direitos Humanos. João Pessoa: CCTA, 2016, p. 38-90. Disponível em:<www.cchla.ufpb.br/.../2016/.../EBOOK-Cultura-e-EDH-América-Latina>. Acesso: 10 Jul. 2017. 